\title{
Vitamin B12 and vitamin D status of older Irish adults: Preliminary results from the BIO-TILDA Study
}

\author{
Eamon Laird ${ }^{1}$, Aisling O’Halloran ${ }^{1}$, Martin Healy ${ }^{2}$, Rose Anne Kenny ${ }^{1}$ and Anne Molloy ${ }^{1}$ \\ ${ }^{1}$ School of Medicine, Trinity College, Dublin 2, Ireland and ${ }^{2}$ The Department of Biochemistry \& Clinical Pathology, St \\ James's Hospital, Dublin 8, Ireland
}

Low vitamin B12 (cobalamin) status is a common finding among the elderly with estimates of those affected ranging from 5-40 \%, depending on the marker of measurement ${ }^{(1)}$. The consequences of a deficient state include the development of megalobalstic anaemia, demyelinating neurological disease/paresthesias and the potential for impaired immune and bone functionality ${ }^{(2)}$. Inadequate vitamin $\mathrm{D}$ status is also a major concern within this population sub-group, particularly in countries at far latitudes such as Ireland $\left(52-55^{\circ} \mathrm{N}\right)$ where dermal synthesis is seasonal and highly dependent on local climate conditions ${ }^{(3)}$. To-date, no large scale representative population studies have examined the status of these micronutrients in older Irish adults.

Samples for the current study were from the Trinity Irish Longitudinal Ageing Study (TILDA). The TILDA study is a nationally representative sample of $>8,000$ older adults aged $50 \mathrm{y}$ and over, resident in Ireland, aimed at investigating the health, social and economic status and needs of older adults and the biological and environmental components of successful ageing. Blood samples were provided from participants in Wave 1 of the TILDA study and analysed for concentrations of vitamin B12 (total plasma cobala$\min )(n 5,454)$ by microbiological assay (colistin resistant L. Delbreuckii). Deficient vitamin B12 status was defined as $<148$, insufficient as $148-185$ and adequate as $>185 \mathrm{pmol} / \mathrm{L}^{(4)}$. Vitamin D (serum $25(\mathrm{OH}) \mathrm{D}$ ) concentrations $(n 4,387)$ were measured by LC-MS/ MS with deficiency defined as $<30$, insufficient as $30-50$ and adequate as $>50 \mathrm{nmol} / \mathrm{L}^{(5)}$. For vitamin D status investigations, summer period was defined as the months of March-September while winter period was defined as the months October-February.

Overall, $10 \cdot 6 \%$ of the population sample had either deficient or inadequate vitamin B12 status. Median total cobalamin concentrations were significantly higher in females $(330.28 \mathrm{pmol} / \mathrm{L})$ compared with males $(308.4 \mathrm{pmol} / \mathrm{L})(\mathrm{P}<0.05)$, and concentrations decreased significantly with increasing age decade $(50-59,60-69,70-79,>80 \mathrm{yrs})(\mathrm{P}<0 \cdot 05)$. Overall, $15 \cdot 3 \%$ of the cohort was vitamin $\mathrm{D}$ deficient while $31.6 \%$ had insufficient status. Median $25(\mathrm{OH}) \mathrm{D}$ concentrations were significantly higher in females $(52.7 \mathrm{nmol} / \mathrm{L})$ compared with males $(46.3 \mathrm{nmol} / \mathrm{L})$, but only for the winter period $(\mathrm{P}<0.05)$. Similar to vitamin $\mathrm{B} 12$, concentrations of $25(\mathrm{OH}) \mathrm{D}$ significantly decreased with increasing age decade (both in summer and winter) $(\mathrm{P}<0.05)$.

These preliminary findings provide new data on the micronutrient status of older Irish adults and will be useful for informing public healthcare planning and policy. Furthermore, the addition of these biomarkers into the TILDA dataset will allow for future in-depth exploration of the relationships between health, nutrition, chronic disease and healthy ageing.

\section{Acknowledgement of Funding}

Funding to conduct this work was provided by the Irish Department of Agriculture, Food and the Marine through the grant 13 F492 the Nutritional Biomarker Database Enhancement Initiative of (“BIO-TILDA”2013-2015).

1. Morris MS, Jacques PF, Rosenberg IH et al. (2002) Am J Clin Nutr 132, 2799-2803.

2. Stabler SP (2013) $N$ Engl J Med 368, 149-160.

3. Laird E, Ward M, McSorley E et al. (2010) Nutrients 7, 693-724.

4. Bailey RL, Carmel R, Green R, et al. (2011) J Clin Nutr 2, 552-561.

5. Institute of Medicine (2010) Washington DC: National Academies Press. 